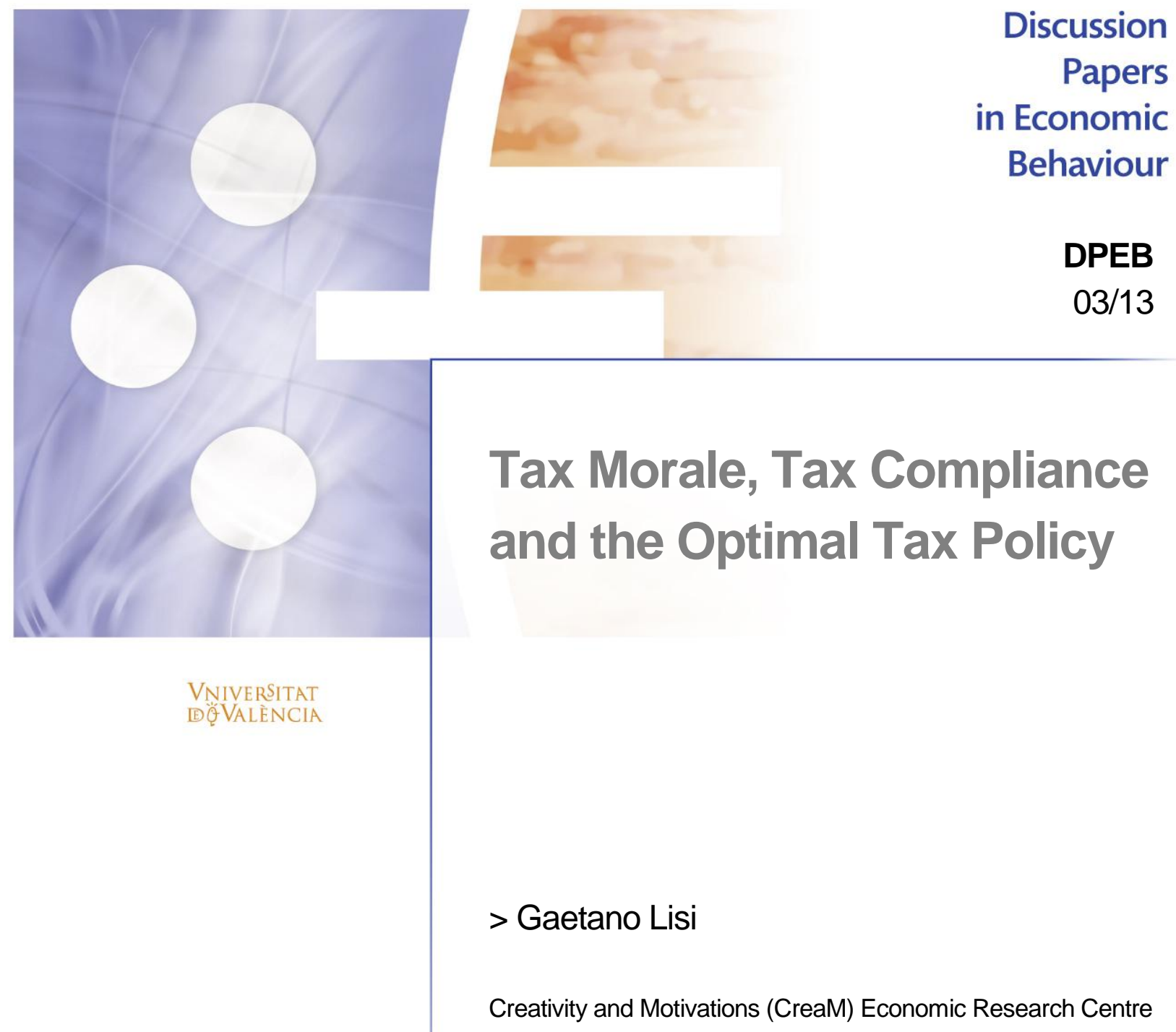

April, 2013 


\title{
Tax Morale, Tax Compliance and the Optimal Tax Policy
}

\section{Gaetano Lisi}

Creativity and Motivations (CreaM) Economic Research Centre, Department of Economics and Law, University of Cassino and Southern Lazio, via S. Angelo, I-03043 Cassino (FR), Italy; Phone: +39 0776 996150; E-mail: gaetano.lisi@unicas.it

\begin{abstract}
Following the behavioural branch of tax compliance literature, this paper tries to incorporate tax morale into the optimal taxation theory. We show that tax morale affects the optimal mix of policy tools of deterrence to clamp down tax evasion. The optimal tax policy in fact differs according to the type of tax payer taken into account. Precisely, in the case of honest taxpayers the optimal strategy from a social welfare standpoint is to substitute a higher taxation/penalty with tighter monitoring; whereas, in the case of tax evaders, the policy maker should enforce both a higher penalty and an increased monitoring.
\end{abstract}

JEL CLASSIFICATION H26, J64, K42

KEYWORDS tax evasion, tax compliance, tax morale, taxation, monitoring 


\section{Introduction}

In an influential paper, Slemrod states that " ... in its current state optimal tax theory is incomplete as a guide to action concerning the ... critical issues in tax policy. It is incomplete because it has not yet come to terms with taxation as a system of coercively collecting revenues from individuals who will tend to resist » $(1990$, p. 157). In particular, the standard theory of optimal taxation does not take into account the phenomenon of tax evasion. It, in fact, presumes that taxes can be fully enforced, whereas the literature on tax compliance clearly shows that this assumption is not realistic (see e.g. Andreoni, Erard and Feinstein 1998). As a result, the empirical relevance of optimal taxation theory and its impact on practical tax policy is weak (Slemrod, 1990). ${ }^{1}$ Indeed, the normative policy implications derived from the existing framework of optimal taxation theory may be misleading, thus recommending the wrong or at least an inadequate measure when tax evasion is feasible. A distortionary commodity tax, in fact, may become part of the optimal tax policy when an efficient income tax can be evaded whereas the distortionary commodity tax cannot (Gueth and Sausgruber, 2004).

In a nutshell, it is the narrowness of the approach which is subject to criticism. In particular, the theory of optimal taxation has put too low an emphasis on the intrinsic motivations of why people pay taxes, i.e. on tax morale (Gueth and Sausgruber, 2004; Torgler and Schaltegger, 2005). The relevance of tax morale for fiscal policy cannot be neglected, since it is able to explain the high degree of tax compliance in the presence, in many countries, of a very low deterrence level (Torgler 2007; Slemrod 2007). ${ }^{2}$ Hence, there is a strong need to incorporate behavioural aspects of tax compliance into the debate on optimal tax policy (Gueth and Sausgruber, 2004; Torgler and Schaltegger, 2005).

Following this important strand of tax compliance literature, this paper tries to incorporate the key role of tax morale into the optimal taxation theory. Precisely, instead of examining the behaviour of taxpayers, we study the normative policy implications (i.e. "what tax authorities might do") in presence of two different kinds of taxpayers: honest taxpayers

\footnotetext{
${ }^{1}$ Based on the assumptions of rational and self-interested taxpayers, the theory of optimal taxation aims to give recommendations on how to develop an efficient tax system such that the cost of taxation is reduced in the best possible way.

2 The relationship between tax compliance and tax policy is at once complex, challenging and fascinating (Torgler, 2008) and the usefulness of going beyond a deterrence approach is evident: the enforcement strategy is connected with high costs (Slemrod, 1992) and predicts far too little compliance and far too much tax evasion (Frey and Feld, 2002). Furthermore, the empirical support for the deterrent effect of audits and fines is weak and unstable (Kirchler et al. 2008).
} 
and tax evaders. Focusing the attention on the diffusion process of tax moral is very important, since this may help policy makers in finding proper interventions to increase tax moral and thus tax compliance. Nevertheless, the bad news is that tax morale is usually regarded as very slowly-changing (Lindbeck and Nyberg 2006; Halla 2010). Hence, it may be even more interesting to study the (different) policy implications (the behaviour of tax authorities) in presence of tax evasion.

We show that tax morale affects the optimal mix of policy tools of deterrence to clamp down tax evasion. The optimal tax policy is, in fact, different according to the type of taxpayer taken into account. Precisely, in the case of honest taxpayers, the optimal strategy from a social welfare standpoint is to substitute a higher taxation/penalty with a tighter monitoring; whereas, in the case of tax evaders, the policy maker should enforce both a higher penalty and an increased monitoring.

Thus, as suggested by the behavioural branch of tax compliance literature (see e.g. Gueth and Sausgruber, 2004; Torgler and Schaltegger, 2005), the behavioural approach to optimal tax policy, which puts emphasis on tax morale, may lead to different conclusions and recommendations for policy makers.

The rest of the paper is organised as follows: section 2 presents the macroeconomic model of tax compliance; while section 3 derives the policy implications in the presence of taxpayers who have different tax morale. Section 4 concludes the work.

\section{A macroeconomic model with tax evasion}

We consider a baseline matching model à la Pissarides (2000) with a continuum of homogeneous workers of measure one and free-entry of one-job firms (small businesses). The utility of using the matching models in this type of analysis is straightforward: on the one hand, these models allow us to obtain macroeconomic outcomes and, on the other side, by the "one-job firms" assumption, they allow us to analyze the behaviour of entrepreneurs and small businesses. Indeed, in most of the studies of tax compliance, research has focused on personal income tax evasion, while studies on tax morale in the case of business tax evasion are very limited (Torgler and Schaltegger, 2005).

In matching-type models, the creation of employment is characterised by trading frictions due to costly and time-consuming matching of workers and firms. Precisely, an aggregate matching function is used to summarise these frictions (Petrongolo and Pissarides, 
2001) and the number of job matches formed per unit of time is $m=m(u, v)$, where $u$ is the number of unemployed workers and $v$ is the number of vacancies. The matching function is strictly increasing but concave in both arguments and displays constant returns to scale. This common assumption allows us to introduce the key variable of the model, $\vartheta \equiv v / u$, more commonly known as 'market tightness'. It follows that $q(\vartheta) \equiv m\{v, u\} / v=m\left\{1, \vartheta^{-1}\right\}$ and $g(\vartheta) \equiv m\{v, u\} / u=m\{\vartheta, 1\}$ are the instantaneous probability of filling a vacancy and of finding a job, respectively. For the sake of simplicity, we express the matching function by the functional form commonly used in matching models, i.e. the Cobb-Douglas function, $m=m(v, u)=v^{1-\alpha} \cdot u^{\alpha}$, where $0<\alpha<1$ is the (constant) elasticity of the matching function with respect to the share of unemployed workers. Hence, $q(\vartheta)=\vartheta^{-\alpha}$ and $g(\vartheta)=\vartheta^{1-\alpha}$. To $^{3}$ To ensure that unemployment exists in steady state, it is assumed that job destruction occurs at the rate $\delta$. Therefore, in steady state the matching and job destruction rates allow us to obtain both the evolution of the unemployment rate over the course of time $(\dot{u})$ and the steady state unemployment rate $(u)$ :

$$
\left\{\begin{array}{l}
\dot{u}=\delta \cdot(1-u)-\vartheta^{1-\alpha} \cdot u \\
u=\frac{\delta}{\delta+\vartheta^{1-\alpha}}
\end{array}\right.
$$

Obviously, with $\partial u / \partial \vartheta<0$, and where $(1-u) \equiv n$ is the share of employed workers.

Compared to the baseline matching model, we only introduce the cost and benefit of tax evasion in the value of a filled job (see Lisi, 2012a, 2012b). Hence, the value functions specified to find infinite horizon steady-state solutions are the following:

\begin{tabular}{c|c} 
value of a vacancy $(V):$ & $r V=-c+q(\vartheta) \cdot(J-V)$ \\
\hline value of a filled job $(J):$ & $r J=y-\tau \cdot\left(y^{D}-w\right)-\rho \varphi \cdot e-w-c(e)+\delta \cdot(V-J)$ \\
\hline value of searching for a job $(U):$ & $r U=b+g(\vartheta) \cdot(W-U)$ \\
\hline value of being employed $(W):$ & $r W=w+\delta \cdot(U-W)$
\end{tabular}

where $r>0$ is the exogenous discounted rate; $c$ is the vacant job cost; $y$ is the true productivity, while $y^{D}$ is the declared one; $\tau$ is the company (corporate) income tax rate; $e \equiv\left(y-y^{D}\right)$ is the evaded income; $w$ is the wage rate (tax deductible); $b$ is the benefit of being unemployed; $\rho$ is the rate whereby tax authorities detect tax evasion and levy the penalty $\varphi$, with $\varphi>\tau$ (a fair penalty, in fact, must be assessed on the level of taxes); $c(e)$ is

\footnotetext{
${ }^{3}$ Standard technical assumptions are assumed: $\lim _{\vartheta \rightarrow 0} q(\vartheta)=\lim _{\vartheta \rightarrow \infty} g(\vartheta)=\infty$, and $\lim _{\vartheta \rightarrow 0} g(\vartheta)=\lim _{\vartheta \rightarrow \infty} q(\vartheta)=0$.
} 
the concealment cost, with $c^{\prime}(e)>0$. Therefore, the higher the evaded income, the greater the penalty and the concealment cost. Furthermore, we assume that the declared income is different within firms and that it depends on the morality of entrepreneurs. Precisely, the declared income is very low for tax evaders; whereas, the opposite is true for the honest entrepreneurs. Formally, $y \geq y_{\text {honest }}^{D}>y_{\text {evader }}^{D} \geq 0$.

As usual, the model is closed by the relationship between market tightness and wage. Precisely, the equilibrium value of market tightness is given by the value of a filled job under the free-entry (or zero profit) condition $V=0$, while the wage is the outcome of a bilateral matching problem described by the Nash bargaining solution: ${ }^{4}$

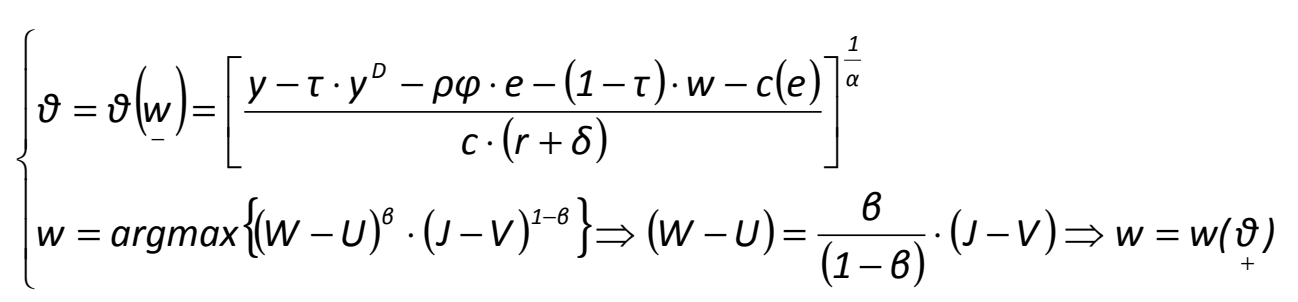

where $b \in(0,1)$ is the bargaining power of workers. By definition, a market with search and matching frictions require positive and finite tightness, i.e. $0<\vartheta<\infty$, since for $\vartheta=0$ the vacancies are always filled, whereas for $\vartheta=\infty$ the job-seekers immediately find a vacant job. Hence, this implies a positive net output per job, i.e. $y-\tau \cdot y^{D}-\rho \varphi \cdot e-(1-\tau) \cdot w-c(e)>0$, which, in turn, depends on the policy parameters, namely the level of taxation, the monitoring rate and the fines.

In the next section, we will show that the optimal mix of policy tools of deterrence crucially depends on the type of firm/entrepreneur taken into account.

\section{The optimal tax policy}

The theory of optimal taxation accounts for social preferences by the concept of social welfare functions. However, it has not dealt with the question of how new assumptions about real behaviour would modify traditional optimal tax rules (Gueth and Sausgruber, 2004). Hence, in the social welfare function we introduce the possibility that the declared income is different within firms and that it depends on the morality of entrepreneurs.

We derive the optimal tax policy, namely the right mix of taxation $\tau$ and monitoring $\rho$, in a context in which a policy-maker maximizes the social output. In turn, the choice of $\tau$

\footnotetext{
${ }^{4}$ The derivation of the solution to the bargaining problem is too standard to be repeated here.
} 
will imply the optimal choice of fines, since the penalty must be higher than the taxation, i.e. $\varphi>\tau$. $^{5}$

Following the textbook of Pissarides (2000), the social welfare function for an infinitely-lived economy is equal to the net output per job, minus vacancies costs, plus the benefit of being unemployed. The policy-maker thus maximizes the following programme:

$$
\left\{\begin{array}{l}
\max \Omega=\int_{0}^{\infty} e^{-r t}\left[\left(y-\tau \cdot y^{D}-\rho \varphi \cdot e-c(e)\right) \cdot n-c \cdot v+b \cdot u\right] d t \\
\text { s.t. } \dot{u}=\delta \cdot(1-u)-g(\vartheta) \cdot u
\end{array}\right.
$$

Let $\lambda$ be co-state variable, i.e. the shadow value of a marginal increase in the state variable $u$ at the time $t$, so that the Hamiltonian $(H)$ is: ${ }^{6}$

$$
H=\left\{e^{-r t} \cdot\left[\left(y-\tau \cdot y^{D}-\rho \varphi \cdot e-c(e)\right) \cdot(1-u)-c \cdot v+b \cdot u\right]+\lambda \cdot[\delta \cdot(1-u)-g(\vartheta) \cdot u]\right\}
$$

The solution to this dynamic maximization problem requires that: ${ }^{7}$

$$
\left\{\begin{array}{l}
\frac{\partial H}{\partial \tau} \Rightarrow-y^{D} \cdot(1-u)-\lambda \cdot \frac{\partial g(\vartheta)}{\partial \tau} \cdot u=0 \\
\frac{\partial H}{\partial \rho} \Rightarrow-\varphi \cdot e \cdot(1-u)-\lambda \cdot \frac{\partial g(\vartheta)}{\partial \rho} \cdot u=0 \\
\frac{\partial H}{\partial u} \Rightarrow-\left(y-\tau \cdot y^{D}-\rho \varphi \cdot e-c(e)\right)+b-\lambda \cdot[\delta+g(\vartheta)]=-(\dot{\lambda}-r \cdot \lambda)
\end{array}\right.
$$

By combining the first two optimality conditions we get:

$$
\left\{\begin{array}{l}
\frac{\partial H}{\partial \tau} \Rightarrow \frac{-y^{D}}{\frac{\partial g(\vartheta)}{\partial \tau}}=\lambda \cdot \frac{u}{(1-u)} \\
\frac{\partial H}{\partial \rho} \Rightarrow \frac{-\varphi \cdot e \cdot}{\frac{\partial g(\vartheta)}{\partial \rho}}=\lambda \cdot \frac{u}{(1-u)} \\
\frac{-y^{D}}{\partial g(\vartheta)} \frac{-\varphi \cdot e \cdot}{\frac{\partial g(\vartheta)}{\partial \tau}} \Rightarrow \varphi \cdot e \cdot \frac{\partial g(\vartheta)}{\partial \tau}=y^{D} \cdot \frac{\partial g(\vartheta)}{\partial \rho}
\end{array}\right.
$$

\footnotetext{
${ }^{5}$ In short, taxation and monitoring are the choice variables of the policy maker, while the penalty is assessed on the level of taxes so that it is always higher than taxation.

${ }^{6}$ The social planner is not interested in wages, since wages only determine the output's distribution and distributional considerations are excluded from the social welfare function. Furthermore, the social planner is subject to the same matching constraints as firms and workers. Hence, the evolution of employment constrains social choices as well as private ones.

${ }^{7}$ Besides the transversality condition, namely $\lim _{t \rightarrow \infty} \lambda \cdot e^{-r \cdot t} \cdot u \geq 0$. The transversality condition is necessary in order to obtain a well-defined optimal solution, namely to avoid that the objective function to be maximized can assume an infinite value.
} 
Total differentiation of the previous condition with respect to $\tau$ and $\rho$ gives the relationship between taxation and monitoring:

$$
\begin{aligned}
& \varphi \cdot e \cdot \frac{\partial^{2} g(\vartheta)}{\partial \tau^{2}} \cdot d \tau+\varphi \cdot e \cdot \frac{\partial^{2} g(\vartheta)}{\partial \tau \partial \rho} \cdot d \rho=y^{D} \cdot \frac{\partial^{2} g(\vartheta)}{\partial \rho^{2}} \cdot d \rho+y^{D} \cdot \frac{\partial^{2} g(\vartheta)}{\partial \rho \partial \tau} \cdot d \tau \\
& \Rightarrow\left[\varphi \cdot e \cdot \frac{\partial^{2} g(\vartheta)}{\partial \tau^{2}}-y^{D} \cdot \frac{\partial^{2} g(\vartheta)}{\partial \rho \partial \tau}\right] \cdot d \tau=\left[y^{D} \cdot \frac{\partial^{2} g(\vartheta)}{\partial \rho^{2}}-\varphi \cdot e \cdot \frac{\partial^{2} g(\vartheta)}{\partial \tau \partial \rho}\right] \cdot d \rho
\end{aligned}
$$

Equation (6) expresses, in general, the optimal rule for tax policy. However, by assuming that the declared income is different within firms and that it depends on the morality of entrepreneurs, the behavioural approach to optimal tax policy leads to different advice for policy makers. Indeed, by taking the extreme cases, we get:

- for tax evaders:

$$
\lim _{e \rightarrow y\left(y^{D} \rightarrow 0\right)}\left[\varphi \cdot y \cdot \frac{\partial^{2} g(\vartheta)}{\partial \tau^{2}}\right] \cdot d \tau=[-\varphi \cdot y \cdot \underbrace{\frac{\partial^{2} g(\vartheta)}{\partial \tau \partial \rho}}_{<0}] \cdot d \rho \Rightarrow \frac{d \tau}{d \rho}>0
$$

- for honest taxpayers:

$$
\lim _{e \rightarrow 0\left(y^{\circ} \rightarrow y\right)}[-y \cdot \underbrace{\frac{\partial^{2} g(\vartheta)}{\partial \rho \partial \tau}}_{>0}] \cdot d \tau=\left[y \cdot \frac{\partial^{2} g(\vartheta)}{\partial \rho^{2}}\right] \cdot d \rho \Rightarrow \frac{d \tau}{d \rho}<0
$$

To the limit, in fact, the evaded income of tax evaders tends to the maximum, i.e. the declared income tends to the minimum: $y^{D} \rightarrow 0$; whereas, the evaded income tends to the minimum for honest taxpayers, i.e. the declared income tends to the maximum: $y^{D} \rightarrow y$. Furthermore, the cross derivatives are different (for the mathematical details see the Appendix, now at the end): in fact, $\frac{\partial^{2} g(\vartheta)}{\partial \rho \partial \tau}>0$ for honest taxpayers and $\frac{\partial^{2} g(\vartheta)}{\partial \tau \partial \rho}<0$ for tax evaders.

As a result, the relationship between taxation and monitoring is negative for honest taxpayers and positive for tax evaders. Therefore, from the social welfare standpoint, two different optimal strategies are obtained:

- In the case of honest taxpayers, the best strategy is to substitute a higher taxation/penalty with a tighter monitoring; in particular, a mix of tax reduction and increased monitoring may be the winning strategy (so as not to bring up doubts about 
the power of tax authorities and enhance trust in the effectiveness and credibility of the tax authorities' work).

- Whereas, in the case of tax evaders, the policy maker should enforce both a higher taxation/penalty and an increased monitoring (this could be the best tax policy in countries like Italy where public spending is very inelastic, public debt is very large and tax morale is very low).

The different treatment of taxpayers by tax authorities may also be useful in the process of diffusion of tax morale: when taxpayers feel that the tax office acts and decides in a procedurally fair manner, they develop positive attitudes towards taxation (Hartner et al., 2008). ${ }^{8}$

Finally, note that by considering the equilibrium of the model, i.e. equation [2], this strategy implies ceteris paribus a lower net output per job for tax evaders, namely a lower convenience to escape. According to Schneider (2008), the big challenge for policy makers is to undertake policy measures that make work in the underground (official) economy less (more) attractive.

\section{Conclusions}

The standard theory of optimal taxation does not take into account the phenomenon of tax evasion. Furthermore, it has put too low an emphasis on the intrinsic motivations regarding why people pay taxes, i.e. on tax morale. Following the behavioural branch of tax compliance literature, this paper tries to incorporate tax morale into the optimal taxation theory. We show that tax morale affects the optimal mix of policy tools of deterrence to clamp down on tax evasion. The optimal tax policy is, in fact, different according to the type of taxpayer taken into account. Precisely, in the case of honest taxpayers, the optimal strategy from a social welfare standpoint is to substitute a higher taxation/penalty with a tighter monitoring; whereas, in the case of tax evaders, the policy maker should enforce both a higher penalty and an increased monitoring. Therefore, as suggested by the behavioural branch of tax compliance literature, the behavioural approach to optimal tax policy leads to different conclusions and recommendations for policy makers.

\footnotetext{
${ }^{8}$ Indeed, if taxpayers believe that they live in a state in which corruption is rampant and trust in authority is low, the willingness to comply with their tax obligations will decrease (Bird et al., 2008).
} 


\section{References}

Andreoni, James, Brian Erard, and Jonathan Feinstein (1998). Tax Compliance, Journal of Economic Perspectives, 36(2), 818-860.

Bird, Richard, Jorge Martinez-Vazquez, and Benno Torgler (2008). Tax Effort in Developing Countries and High Income Countries: The Impact of Corruption, Voice and Accountability, Economic Analysis and Policy, 38(1), 55-71.

Feld, Lars P., and Bruno S. Frey (2002). Trust Breeds Trust: How Taxpayers Are Treated, Economics of Governance, 3(2), 87-99.

Gueth, Werner, and Rupert Sausgruber (2004). Tax Morale and Optimal Taxation, CESIFO Working Paper Series, 1284.

Halla, Martin (2012). Tax Morale and Compliance Behavior: First Evidence on a Causal Link, The B.E. Journals of Economic Analysis and Policy, 12(1), pages 13.

Hartner, Martina, Silvia Rechberger, Erich Kirchler, and Alfred Schabmann (2008). Procedural Fairness and Tax Compliance, Economic Analysis and Policy, 38(1), 137-152.

Kirchler, Erich, Stephan Muehlbacher, Barbara Kastlunger, and Ingrid Wahl (2008). Why Pay Taxes? A Review of Tax Compliance Decisions, in: Jorge Martinez-Vazquez, Benno Torgler, and James Alm (Edition) Developing Alternative Frameworks for Explaining Tax Compliance, Abingdon, Oxon: Routledge.

Lindbeck, Assar, and Sten Nyberg (2006). Raising Children to Work Hard: Altruism, Work Norms, and Social Insurance. The Quarterly Journal of Economics, 121(4), 1473-1503.

Lisi, G. (2012a). Unemployment, tax evasion and the slippery slope framework, International Review of Economics, 59(3), 297-302.

Lisi, G. (2012b). Macroeconomic implications of the dynamics between power and trust: a theoretical formalisation of the 'slippery slope' framework, Discussion Papers in Economic Behaviour, DPEC 1012, University of Valencia, ERI-CES.

Petrongolo, Barbara, and Christopher A. Pissarides (2001). Looking into the Black Box: A Survey of the Matching Function, Journal of Economic Literature, 39(2), 390-431.

Pissarides, Christopher A. (2000). Equilibrium Unemployment Theory, $2^{\text {nd }}$ Edition, MIT Press.

Schneider, Friedrich (2008). The Shadow Economy in Germany: A Blessing or a Curse for the Official Economy?, Economic Analysis and Policy, 38(1), 89-111.

Slemrod, Joel (1990). Optimal Taxation and Optimal Tax Systems, Journal of Economic Perspectives, 4(1), 157-178.

Slemrod, Joel (1992). Why People Pay Taxes: Tax Compliance and Enforcement, Ann Arbor: University of Michigan Press.

Slemrod, Joel (2007). Cheating Ourselves: The Economics of Tax Evasion, Journal of Economic Perspectives, 21(1), 25-48.

Torgler, Benno (2007). Tax Compliance and Tax Morale: A Theoretical and Empirical Analysis. Cheltenham, Edward Elgar.

Torgler, Benno (2008). Introduction to the Special Issue on Tax Compliance and Tax Policy, Economic Analysis and Policy, 38(1), 31-33.

Torgler, Benno, and Christoph A. Schaltegger (2005). Tax Morale and Fiscal Policy, CREMA Working Paper, 2005-30. 


\section{Appendix}

Relationship between taxation and market tightness (recall that $\left.\frac{\partial g(\vartheta)}{\partial \vartheta}=(1-\alpha) \cdot \vartheta^{-\alpha}>0\right)$. Honest taxpayers:

$$
\begin{aligned}
& \frac{\partial \vartheta}{\partial \tau}=\frac{1}{\alpha} \cdot\left[\frac{y-\tau \cdot y^{D}-\rho \varphi \cdot e-(1-\tau) \cdot w-c(e)}{c \cdot(r+\delta)}\right]^{\frac{1-\alpha}{\alpha}} \cdot\left[\frac{-y^{D}+w}{c \cdot(r+\delta)}\right]<0 \\
& \frac{\partial^{2} \vartheta}{\partial \tau^{2}}=\frac{1-\alpha}{\alpha} \cdot \frac{1}{\alpha} \cdot\left[\frac{y-\tau \cdot y^{D}-\rho \varphi \cdot e-(1-\tau) \cdot w-c(e)}{c \cdot(r+\delta)}\right]^{\frac{1-\alpha}{\alpha}-1} \cdot\left[\frac{-y^{D}+w}{c \cdot(r+\delta)}\right]^{2}>0 \\
& \frac{\partial^{2} \vartheta}{\partial \tau \partial \rho}=\frac{1-\alpha}{\alpha} \cdot \frac{1}{\alpha} \cdot\left[\frac{y-\tau \cdot y^{D}-\rho \varphi \cdot e-(1-\tau) \cdot w-c(e)}{c \cdot(r+\delta)}\right]^{\frac{1-\alpha}{\alpha}-1} \cdot\left[\frac{-y^{D}+w}{c \cdot(r+\delta)}\right] \cdot\left[\frac{-\varphi \cdot e}{c \cdot(r+\delta)}\right]>0
\end{aligned}
$$

Tax evaders:

$$
\begin{aligned}
& \frac{\partial \vartheta}{\partial \tau}=\frac{1}{\alpha} \cdot\left[\frac{y-\tau \cdot y^{D}-\rho \varphi \cdot e-(1-\tau) \cdot w-c(e)}{c \cdot(r+\delta)}\right]^{\frac{1-\alpha}{\alpha}} \cdot\left[\frac{-y^{D}+w}{c \cdot(r+\delta)}\right]>0 \\
& \frac{\partial^{2} \vartheta}{\partial \tau^{2}}=\frac{1-\alpha}{\alpha} \cdot \frac{1}{\alpha} \cdot\left[\frac{y-\tau \cdot y^{D}-\rho \varphi \cdot e-(1-\tau) \cdot w-c(e)}{c \cdot(r+\delta)}\right]^{\frac{1-\alpha}{\alpha}-1} \cdot\left[\frac{-y^{D}+w}{c \cdot(r+\delta)}\right]^{2}>0 \\
& \frac{\partial^{2} \vartheta}{\partial \tau \partial \rho}=\frac{1-\alpha}{\alpha} \cdot \frac{1}{\alpha} \cdot\left[\frac{y-\tau \cdot y^{D}-\rho \varphi \cdot e-(1-\tau) \cdot w-c(e)}{c \cdot(r+\delta)}\right]^{\frac{1-\alpha}{\alpha}-1} \cdot\left[\frac{-y^{D}+w}{c \cdot(r+\delta)}\right] \cdot\left[\frac{-\varphi \cdot e}{c \cdot(r+\delta)}\right]<0
\end{aligned}
$$

Relationship between monitoring and market tightness

$$
\begin{aligned}
& \frac{\partial \vartheta}{\partial \rho}=\frac{1}{\alpha} \cdot\left[\frac{y-\tau \cdot y^{D}-\rho \varphi \cdot e-(1-\tau) \cdot w-c(e)}{c \cdot(r+\delta)}\right]^{\frac{1-\alpha}{\alpha}} \cdot\left[\frac{-\varphi \cdot e}{c \cdot(r+\delta)}\right]<0 \\
& \frac{\partial^{2} \vartheta}{\partial \rho^{2}}=\frac{1-\alpha}{\alpha} \cdot \frac{1}{\alpha} \cdot\left[\frac{y-\tau \cdot y^{D}-\rho \varphi \cdot e-(1-\tau) \cdot w-c(e)}{c \cdot(r+\delta)}\right]^{\frac{1-\alpha}{\alpha}-1} \cdot\left[\frac{-\varphi \cdot e}{c \cdot(r+\delta)}\right]^{2}>0
\end{aligned}
$$

Honest taxpayers:

$$
\frac{\partial^{2} \vartheta}{\partial \rho \partial \tau}=\frac{1-\alpha}{\alpha} \cdot \frac{1}{\alpha} \cdot\left[\frac{y-\tau \cdot y^{D}-\rho \varphi \cdot e-(1-\tau) \cdot w-c(e)}{c \cdot(r+\delta)}\right]^{\frac{1-\alpha}{\alpha}-1} \cdot\left[\frac{-\varphi \cdot e}{c \cdot(r+\delta)}\right] \cdot\left[\frac{-y^{D}+w}{c \cdot(r+\delta)}\right]>0
$$

Tax evaders:

$$
\frac{\partial^{2} \vartheta}{\partial \rho \partial \tau}=\frac{1-\alpha}{\alpha} \cdot \frac{1}{\alpha} \cdot\left[\frac{y-\tau \cdot y^{D}-\rho \varphi \cdot e-(1-\tau) \cdot w-c(e)}{c \cdot(r+\delta)}\right]^{\frac{1-\alpha}{\alpha}-1} \cdot\left[\frac{-\varphi \cdot e}{c \cdot(r+\delta)}\right] \cdot\left[\frac{-y^{D}+w}{c \cdot(r+\delta)}\right]<0
$$

These results follow from the assumption that the declared income is very low for tax evaders (to the limit, in fact $y^{D} \rightarrow 0$ ); whereas, to the limit, $y^{D} \rightarrow y$ for honest taxpayers. Thus, since 
the wage is positive: $-y^{D}+w>0$ for tax evaders (thus, they declare losses) and the opposite is true for the honest taxpayers, i.e. $-y^{D}+w<0$. 